\title{
Anemia in Patients with Chronic Obstructive Pulmonary Disease in a Tertiary Care Hospital in Bangladesh
}

\author{
Naser Ahmed ${ }^{1}$, Rukhsana Parvin ${ }^{2}$, Md. Abul Kalam Azad ${ }^{3}$ \\ Received: January 10, 2014 Accepted: June 16, 2014
}

\begin{abstract}
Background: Chronic obstructive pulmonary disease (COPD) is usually associated with polycythemia. It is assumed that systemic inflammatory components of COPD can interfere with erythropoietin and can result in anemia of chronic disease which will impair the functional capacity of these patients and also increase morbidity and mortality. Objective: To evaluate anemia status in COPD patients. Materials and Methods: This cross-sectional study was conducted in clinically stable 50 COPD patients in the outpatient department of Medicine in Bangabandhu Sheikh Mujib Medical University (BSMMU), Dhaka during the period of July to December 2011. The demographic characteristics, smoking habit, duration of disease, types and severity of anemia, BMI and results of 6-minute walk test were recorded. Results: Out of 50 COPD patients, $76 \%$ were male and $24 \%$ were female. Among them $32 \%$ patients were anemic, $20 \%$ were polycythemic and $48 \%$ patients had normal hemoglobin. Among the anemic patients with COPD, $87 \%$ were male and $13 \%$ were female,75\% were mildly anemic and 4\% moderately anemic, 62.5\% had normocytic and $37.5 \%$ had microcytic anemia. Conclusion: Anemia in COPD patients is often overlooked and underestimated. Clinicians should be aware of the presence of anemia in patients with COPD so that appropriate treatment could be initiated to improve the quality of life and prognosis.
\end{abstract}

Key words: Anemia; COPD; Smoking; BMI; 6-minute walk test

J Enam Med Col 2014; 4(3): 151-155

\section{Introduction}

A clinical diagnosis of COPD should be considered in any patient who has dyspnea, chronic cough or sputum production, and a history of exposure to risk factors for the disease. Spirometry is required to make the diagnosis in this clinical context, the presence of a postbronchodilator $\mathrm{FEV}_{1} / \mathrm{FVC}<0.70$ confirms the presence of persistent airflow limitation and thus of COPD. ${ }^{1}$ Symptoms are productive cough and dyspnea that are developed over years. Common signs include decreased breath sounds, prolonged expiratory phase of respiration and wheeze. Severe cases may be complicated by weight loss, pneumothorax, frequent acute decompensation episodes, right heart failure and acute or chronic respiratory failure. Diagnosis is based on history, physical examination, chest radiography and pulmonary function tests. Treatment is with bronchodilators, corticosteroids and if necessary, $\mathrm{O}_{2}$ and antibiotics.

COPD comprises chronic bronchitis (clinically defined) and emphysema (pathologically or radiologically defined). ${ }^{2}$ According to World Health Organization (WHO), COPD is the fourth cause of death in developed countries and fifth in the world. ${ }^{3}$ Anemia, as an associated comorbidity, has been proven as an independent marker of mortality in several pathologies such as cardiovascular and renal diseases. This association can also negatively influence several functional parameters and the patient's quality of life. ${ }^{4}$ However, there is limited information in current

1. Classified Specialist, Department of Medicine, Combined Military Hospital, Dhaka

2. Associate Professor, Department of Medicine, Enam Medical College \& Hospital, Savar, Dhaka

3. Associate Professor, Department of Medicine, Bangabandhu Sheikh Mujib Medical University, Dhaka

Correspondence Rukhsana Parvin,Email: rukhsana_parvin@yahoo.com 
literature describing the level of hemoglobin $(\mathrm{Hb})$ and its impact on outcomes in the COPD. Anemia of chronic disease (ACD), with chronically low levels of circulating $\mathrm{Hb}$, is an immune driven abnormality that occurs in many inflammatory diseases and also in chronic heart failure. If present in COPD, anemia could worsen dyspnea and limit exercise tolerance. ${ }^{5}$

Untreated hypoxemia is associated with secondary erythrocytosis, but like other chronic diseases, COPD potentially could affect hematopoiesis. The observed hematopoietic suppression in chronic inflammatory diseases is mediated by three different mechanisms such as shortened red blood cell survival, bone marrow erythropoietin resistance, and dysregulation of iron homeostasis. Underlying factors influencing these aforementioned mechanisms are thought to be related to smoking and smoking-related morbidities, malnutrition and probably the systemic inflammation that accompanies COPD. Systemic inflammation in COPD has been characterized by elevations in levels of IL-6, IL-8, CRP, and TNF- $\alpha$ with the later two mediators potentially contributing to a reduction in red blood cells lifespan, impaired iron utilization, and increased erythropoietin resistance. ${ }^{6}$

Agusti et $\mathrm{al}^{7}$ found that anemic patients showed a significantly higher modified Medical Research Council dyspnea scale score (2.8 versus 2.6), lower 6-minute walk test (265 versus 325 meter) and shorter median survival (49 versus 74 months) than nonanemic patients. In regression models, anemia independently predicted dyspnea and reduced exercise capacity. ${ }^{7}$

COPD patients with low hemoglobin levels have a poorer prognosis than patients with normal hemoglobin levels. Raising hemoglobin through transfusion decreases minute ventilation and work of breathing in COPD patients. ${ }^{5}$ This study was done to find out the frequency of anemia in COPD patients in a tertiary hospital in Bangladesh and to aware the physicians to diagnose it and to treat the patients accordingly.

\section{Materials and Methods}

This cross-sectional study was done in clinically stable 50 COPD patients attending in outpatient department of Medicine of Bangabandhu Sheikh Mujib Medical University (BSMMU) during the period of July to December 2011. COPD was defined by history of dyspnea, chronic cough or sputum production and history of exposure to risk factors and a ratio of $\mathrm{FEV}_{1}$ (forced expiratory volume in $1^{\text {st }}$ second) to FVC (forced vital capacity) $<0.7$ measured 20 minutes after administration of broncodilator (salbutamol). Patients were defined as clinically stable if they had no hospital admission, respiratory infection or exacerbation in prior three months. Patients with bronchial asthma (defined as an increase in $\mathrm{FEV}_{1}$ by $200 \mathrm{~mL}$ or $15 \%$ above the baseline value after administration of a bronchodilator), history of myocardial infarction within the preceding four months, unstable angina, congestive heart failure, thyroid disease, liver disease, renal disease, gastrointestinal or other hemorrhage, blood transfusion within the last three months and any malignancy were excluded from the study.

Anemia was defined as a hemoglobin level of $<12 \mathrm{~g} / \mathrm{dL}$ for women and $<13 \mathrm{~g} / \mathrm{dL}$ for men, according to WHO criteria. ${ }^{8}$ All study subjects underwent peripheral venous blood sampling to determine complete blood count, peripheral blood film, serum levels of urea, creatinine, liver transaminases and total protein. Body mass index (BMI) of all patients was recorded and 6minute walk test was performed. All data were documented in individual case record form. Statistical analysis was done by computer software (SPSS version 12.0).

Prior to the commencement of the study the research protocol was approved by Ethical Review Committee. Written informed consent was taken from each patient after informing them the objective of the study, the risks and benefits, confidential handling of personal information and the voluntary nature of participation and the rights to withdraw from the study.

\section{Results}

Among 50 COPD patients, $76 \%$ were male and $24 \%$ were female. Table I shows distribution of study subjects according to different age groups, duration of smoking and duration of disease. Four patients were between $40-50$ years, 16 between $51-60$ years, 22 between $61-70$ years and 8 were between $71-80$ years. Majority of the patients (92\%) were smokers. Twenty two patients had history of smoking for 25-30 pack year, 20 patients had 20-25 pack year and 4 patients had history of smoking for more than 30 pack year. Only 4 patients were nonsmokers. Total 14 patients had COPD for more than 20 years, 24 for 10-20 years and only 12 patients for less than 10 years. 
Table I: Distribution of patients with COPD according to age, duration of smoking and duration of disease $(n=50)$

\begin{tabular}{|l|c|c|}
\hline Variables & Number & Percentage \\
\hline $\begin{array}{l}\text { Age } \text { in years } \\
40-50\end{array}$ & 4 & 8 \\
\hline $51-60$ & 16 & 32 \\
\hline $61-70$ & 22 & 44 \\
$71-80$ & 8 & 16 \\
\hline Duration of smoking (pack year) & & \\
\hline $25-30$ & 22 & 44 \\
$20-25$ & 20 & 40 \\
\hline 30 & 4 & 8 \\
\hline 0 & 4 & 8 \\
\hline Duration of disease & & \\
\hline 5 years & 4 & 8 \\
\hline $5-10$ years & 8 & 16 \\
\hline $10-15$ years & 12 & 24 \\
$15-20$ years & 12 & 24 \\
$>20$ years & 14 & 28 \\
\hline
\end{tabular}

Among 50 COPD patients, 32\% were anemic, $20 \%$ were polycythemic and $48 \%$ patients had normal $\mathrm{Hb}$ (Table II). Among the anemic patients with COPD, $87 \%$ were male and $13 \%$ were female. Table III shows that among the anemic patients with COPD, $75 \%$ were mildly anemic and $25 \%$ were moderately anemic; $62.5 \%$ had normocytic and $37.5 \%$ had microcytic anemia.

Table II: Hemoglobin status of study subjects $(\mathrm{n}=50)$

\begin{tabular}{|l|c|c|}
\hline Hb status & Number & Percentage \\
\hline Anemic & 16 & 32 \\
\hline Polycythemic & 10 & 20 \\
\hline Normal & 24 & 48 \\
\hline
\end{tabular}

Table III: Severity and types of anemia in COPD patients $(n=16)$

\begin{tabular}{|c|c|c|}
\hline Anemia & Number & Percentage \\
\hline Severity & & \\
\hline Mild & 12 & 75 \\
\hline Male $(10-12.9 \mathrm{~g} / \mathrm{dL})$ & & \\
\hline Female $(10-11.9 \mathrm{~g} / \mathrm{dL})$ & & \\
\hline Moderate $(7-9.8 \mathrm{~g} / \mathrm{dL})$ & 4 & 25 \\
\hline Severe $(<7 g / d L)$ & 0 & 0 \\
\hline Types & & \\
\hline Normocytic & 10 & 62.5 \\
\hline Microcytic & 6 & 37.5 \\
\hline
\end{tabular}

Table IV shows BMI and 6-minute walk test values in anemic and nonanemic COPD patients. Nonanemic patients could perform the test better than anemic patients. COPD patients with relatively high BMI were more prone to be anemic. There is significant difference in BMI between anemic and nonanemic patients $(\mathrm{P}<0.05)$.

Table IV: BMI and 6-minute walk test values in study subjects

\begin{tabular}{|l|c|c|c|}
\hline Variables & $\begin{array}{c}\text { Anemic } \\
(\mathrm{n}=16)\end{array}$ & $\begin{array}{c}\text { Nonanemic } \\
(\mathrm{n}=34)\end{array}$ & P value \\
\hline BMI & $22.1 \pm 2$ & $20.4 \pm 2$ & $<0.05$ \\
\hline $\begin{array}{l}\text { 6-min walk test } \\
\text { (in meter) }\end{array}$ & $207 \pm 32$ & $287 \pm 40$ & $<0.05$ \\
\hline
\end{tabular}

\section{Discussion}

A large portion of COPD patients remain hypoxemic which contribute to polycythemia. Although COPD is usually associated with polycythemia, its systemic inflammatory components can interfere with erythropoietin and result in anemia of chronic disease. There is no feasibility of regular health check-up due to various factors. Lack of knowledge and/or ignorance of signs and symptoms of anemia hinder early diagnosis of anemia. Patients with COPD usually come to a physician or other health care providers due to shortness of breath; so anemia may be overlooked. Patients with COPD also cannot eat well due to respiratory difficulty which leads to nutritional anemia.

In this study, among fifty COPD patients, 38 were male and 12 were female. Males were more affected than females, as smoking was more common in males. Maximum number of COPD patients were in the age group of 61-70 years. A study done by Shorr et $\mathrm{al}^{9}$ in 2008 revealed that anemic patients are older and more likely to be male. Another study done by Chambellan et $\mathrm{al}^{10}$ found that $21 \%$ patients were anemic with concomitant COPD and most of them were elderly.

In this study, 32\% COPD patients were anemic. A study done by Stanbrook ${ }^{11}$ found the prevalence of anemia $36 \%$ in COPD patients randomly selected from outpatient clinic. Another study done by Park et $\mathrm{al}^{12}$ in which 58 patients were enrolled, the frequency was found $48 \%$. John et $\mathrm{al}^{13}$ evaluated anemia and inflammation in COPD patients and found prevalence of anemia $13 \%$ in patients with COPD. Two studies utilizing the International Classification of Diseases 
(ICD-9 or ICD-10) codes for hospital discharge diagnoses found that $21 \%$ and $23 \%$ of COPD patients had anemia. ${ }^{14,15}$ Cote et $\mathrm{al}^{16}$ and John et $\mathrm{al}^{13}$ used the World Health Organization's criteria ${ }^{8}$ for diagnosis of anemia and found it in $13 \%$ and $17 \%$ in their study samples of COPD patients. Thus the prevalence of coexisting anemia in patients with COPD is highly variable.

In this study, among the anemic patients with COPD, $87 \%$ were male and $13 \%$ were female. A study done by Lainscak $^{17}$ revealed that women were significantly more likely than men to be anemic ( $21 \%$ versus $12 \%$, $\mathrm{P}<0.001)$.

The frequency of mild, moderate and severe anemia was $75 \%, 25 \%$ and $0 \%$ respectively in this study. A study done by Boutou et al ${ }^{18}$ found mild anemia in all patients. In present study, the most common variety of anemia was normochromic normocytic anemia (62.5\%). The reasons may be multifactorial, specially due to anemia of chronic disease. In a study done by Tsantes et $\mathrm{al}^{17}$, macrocytosis (defined as MCV $>94 \mathrm{fL}$ ) was found in $43.75 \%$ patients with COPD. The cause is still poorly understood. Another study conducted by García-Pachón and Padilla-Navas ${ }^{20}$ also revealed the prevalence of macrocytosis in 29\% COPD patients.

There are few studies which showed impact of anemia on COPD patients. Anemia reduces exercise tolerance effort and increases dyspnea. Anemic COPD patients are less capable to perform 6-minute walk test than nonanemic COPD patients. Cote et $\mathrm{al}^{16}$ demonstrated that anemia was independently associated with increased dyspnea, by means of modified Medical Research Council (MRC) dyspnea scale and reduced exercise capacity measured by 6-minute walk distance in a cohort of stable COPD patients. In our patients, nonanemic patients could perform the test better than anemic patients. Another study done by Cassanova et $\mathrm{al}^{21}$ found no difference with respect to the dyspnea scale or in meters covered in the 6-minute walk test.

In this study COPD patients with high BMI were found to be anemic and there is a significant difference in BMI between anemic and nonanemic patients $(\mathrm{P}<0.05)$. Chambellan et $\mathrm{al}^{10}$ found that there is a positive correlation between BMI and anemia in COPD patients.

This study shows that near about one-third of COPD patients are anemic with predominance of normocytic anemia. Most of the patients are male and disease duration is mostly more than 10 years. The present study is limited by a small number of patients. We recommend multicentered trial with large sample to find out the prevalence of anemia in COPD patients, to determine the correlation of anemia with disease severity and to follow-up the patients after appropriate treatment.

\section{References}

1. Zwar NA, Marks GB, Hermiz O, Middleton S, Comino EJ, Hasan I et al. Predictors of accuracy of diagnosis of chronic obstructive pulmonary disease in general practice. Med J Aust 2011; 195(4): 168-171.

2. Weiss G, Goodnough LT. Anemia of chronic disease. N Engl J Med 2005; 352: 1011-1023.

3. The top 10 causes of death. World Health Organization fact sheet (Updated May 2014). Available at: http:// who.int/mediacentre/factsheets/fs310/en/. Accessed August 2014.

4. Means RT Jr. Recent developments in the anemia of chronic disease. Curr Hematol Rep 2003; 2: 116-121.

5. Ezekowitz JA, McAlister FA, Armstrong PW. Anemia is common in heart failure and is associated with poor outcomes: insights from a cohort of 12065 patients with new-onset heart failure. Circulation 2003; 107: 223-225.

6. Oudijk EJ, Lammers JW, Koenderman L. Systemic inflammation in chronic obstructive pulmonary disease. Eur Respir J Suppl 2003; 22(Suppl 46): 5s-13s.

7. Agusti AG, Noguera A, Sauleda J, Sala E, Pons J, Busquets $\mathrm{X}$. Systemic effects of chronic obstructive pulmonary disease. Eur Respir J 2003; 21: 347-360.

8. World Health Organization. Nutritional anemia: report of a WHO Scientific Group. In: WHO Technical Report Series 405. Geneva, World Health Organization 1968: 1-37.

9. Shorr AF, Doyle J, Stern L, Dolgitser M, Zilberberg MD. Anemia in chronic obstructive pulmonary disease: epidemiology and economic implications. Curr Med Res Opin 2008; 24: 1123-1130.

10. Chambellan A, Chailleux E, Similowski T. Prognostic value of the hematocrit in patients with severe COPD receiving long-term oxygen therapy. Chest 2005; 128(3): 1201-1208.

11. Stanbrook MB. The prevalence of anemia in chronic obstructive pulmonary disease. Am J Respir Crit Care Med 2003; 167: A235.

12. Park MM, Durrani M, Zilberberg M. Correlation of severity of anemia with severity of COPD. Am J Respir Crit Care Med 2003; 167: A234. 
13. John M, Hoernig S, Doehner W, Okonko DD, Witt C, Anker SD. Anemia and inflammation in COPD. Chest 2005; 127(3): 825-829.

14. Halpern MT, Zilberberg MD, Schmier JK, Lau EC, Shorr AF. Anemia, costs and mortality in chronic obstructive pulmonary disease. Cost Eff Resour Alloc 2006; 4: 17.

15. John M, Lange A, Hoernig S, Witt C, Anker SD. Prevalence of anemia in chronic obstructive pulmonary disease: comparison to other chronic diseases. Int J Cardiol 2006; 111(3): 365-370.

16. Cote C, Zilberberg MD, Mody SH, Dordelly LJ, Celli B. Haemoglobin level and its clinical impact in a cohort of patients with COPD. Eur Respir J 2007; 29(5): 923-929.

17. Lainscak M, Sarc I, Ziherl K, Jeric T, Suskovic S, Kosnik M. Chest 2009; 136(4_Meeting Abstracts):15S. doi:10.1378/ chest.136.4_MeetingAbstracts.15S-g.
18. Boutou AK, Stanopoulos I, Pitsiou GG, Kontakiotis T, Kyriazis G, Sichletidis L et al. Anemia of chronic disease in chronic obstructive pulmonary disease: a case-control study of cardiopulmonary exercise responses. Respiration 2011; 82(3): 237-245.

19. Tsantes AE, Papadhimitriou SI, Tassiopoulos ST, Bonovas S, Paterakis G, Meletis I et al. Red cell macrocytosis in hypoxemic patients with chronic obstructive pulmonary disease. Respir Med 2004; 98(11): 1117-1123.

20. García-Pachón E, Padilla-Navas I. Red cell macrocytosis in COPD patients without respiratory insufficiency: a brief report. Respir Med 2007; 101(2): 349-352.

21. Casanova LC, Echave-Sustaeta JM, Luján RG, Lozano IA, González PA, Alonso MJL. Prevalence of anaemia associated with chronic obstructive pulmonary disease. Study of associated variables. Arch Bronconeumol 2013; 49: 383-387. 